\title{
The Activity of JmjC Histone Lysine Demethylase KDM4A is Highly Sensitive to Oxygen Concentrations
}

\author{
Rebecca L Hancock, ${ }^{\dagger, \ddagger}$ Norma Masson, ${ }^{\S}$ Kate Dunne, ${ }^{\dagger, \ddagger}$ Emily Flashman, ${ }^{*, \dagger}$ and Akane Kawamura $*, \dagger, \ddagger$ \\ ${ }^{\dagger}$ Chemistry Research Laboratory, 12 Mansfield Road, Oxford OX1 3TA, United Kingdom \\ ${ }^{\ddagger}$ Radcliffe Department of Medicine, Division of Cardiovascular Medicine, BHF Centre of Research Excellence, Wellcome Trust \\ Centre for Human Genetics, Roosevelt Drive, Oxford OX3 7BN, United Kingdom \\ ${ }^{\S}$ Target Discovery Institute, NDM Research Building, University of Oxford, Roosevelt Drive, Oxford OX3 7BN, United Kingdom
}

\section{Supporting Information}

ABSTRACT: The JmjC histone lysine demethylases (KDMs) are epigenetic regulators involved in the removal of methyl groups from post-translationally modified lysyl residues within histone tails, modulating gene transcription. These enzymes require molecular oxygen for catalytic activity and, as 2-oxoglutarate (2OG)-dependent oxygenases, are related to the cellular oxygen sensing HIF hydroxylases PHD2 and FIH. Recent studies have indicated that the activity of some KDMs, including the pseudogene-encoded $\mathrm{KDM} 4 \mathrm{E}$, may be sensitive to changing oxygen concentrations. Here, we report detailed analysis of the effect of oxygen availability on the activity of the KDM4 subfamily member KDM4A, importantly demonstrating a high level of $\mathrm{O}_{2}$ sensitivity both with isolated protein and in cells. Kinetic analysis of the recombinant enzyme revealed a high

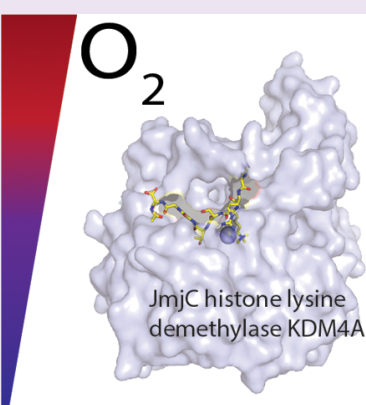

Histone H3 K9me3 $\frac{\mathrm{O}_{2}}{2 \mathrm{KG}_{1} \mathrm{Fe}^{2+}}$ Histone H3 K9me2 $K_{\mathrm{M}}{ }^{\text {app }}\left(\mathrm{O}_{2}\right)$ of $173 \pm 23 \mu \mathrm{M}$, indicating that the activity of the enzyme is able to respond sensitively to a reduction in oxygen concentration. Furthermore, immunofluorescence experiments in U2OS cells conditionally overexpressing KDM4A showed that the cellular activity of KDM4A against its primary substrate, H3K9me3, displayed a graded response to depleting oxygen concentrations in line with the data obtained using isolated protein. These results suggest that KDM4A possesses the potential to act as an oxygen sensor in the context of chromatin modifications, with possible implications for epigenetic regulation in hypoxic disease states. Importantly, this correlation between the oxygen sensitivity of the catalytic activity of KDM4A in biochemical and cellular assays demonstrates the utility of biochemical studies in understanding the factors contributing to the diverse biological functions and varied activity of the $2 \mathrm{OG}$ oxygenases.

\section{INTRODUCTION}

The organization of genetic material into chromatin enables not only the compaction of DNA in the nucleus but also the dynamic regulation of gene transcription. Changes to chromatin structure affect the accessibility of the DNA to the transcriptional machinery and are mediated by hundreds of chromatin-interacting proteins in response to various stimuli. One such family of chromatin-interacting proteins are the Jumonji-C-domain-containing histone lysine demethylases (JmjC-KDMs), which catalyze the removal of methyl groups from $N^{\varepsilon}$-methylated lysyl residues on histone tails, one of numerous known post-translational modifications. ${ }^{1}$ Lysyl residues at positions $4,9,27,36$, and 79 of histone $3(\mathrm{H} 3)$ may be mono-, di- or tri- $N^{\varepsilon}$-methylated, with methylation at residues $\mathrm{H} 3 \mathrm{~K} 4$ and $\mathrm{H} 3 \mathrm{~K} 36$ generally associated with active genes and methylation at residues $\mathrm{H} 3 \mathrm{~K} 9$ and $\mathrm{H} 3 \mathrm{~K} 27$ with transcriptional repression. The KDM4 subfamily of enzymes catalyze demethylation of tri- and dimethylated H3K9 (H3K9me2/3), H3K36me2/3 marks as well as mono- and dimethylated histone 1.4 lysine $26(\mathrm{H} 1.4 \mathrm{~K} 26 \mathrm{me} 1 / 2){ }^{2,3}$
The JmjC-KDMs are members of the $\mathrm{Fe}^{2+}$ and 2-oxoglutarate (2OG)-dependent oxygenase superfamily, which are characterized by a conserved double-stranded $\beta$ helix (DSBH) fold and share many mechanistic features. ${ }^{4,5}$ There are over 60 known human $2 \mathrm{OG}$ oxygenases, all of which use molecular oxygen as a co-substrate in their catalysis of a range of reactions in varied biological contexts. Some of the more well characterized members of this superfamily include the prolyl hydroxylase domain enzymes 1-3 (PHD1-3) and factor-inhibiting HIF (FIH), collectively termed the HIF hydroxylases. These enzymes are responsible for the regulation of hypoxia inducible factor (HIF), a transcription factor which is considered the master regulator of the cellular hypoxic response. ${ }^{6}$ In normoxia, the PHD enzymes catalyze hydroxylation of HIF at two prolyl residues in its oxygen-dependent degradation domain, targeting HIF for proteasomal degradation, while FIH catalyzes hydroxylation of

\footnotetext{
Received: October 31, 2016

Accepted: January 4, 2017

Published: January 4, 2017
} 
an asparaginyl residue in the $C$-terminal activation domain of HIF, ablating its interaction with transcriptional coactivators. ${ }^{7}$ The HIF hydroxylases act as oxygen sensors such that in moderate hypoxia, their activity is inhibited, allowing HIF to activate hundreds of target genes ${ }^{8}$ such as those encoding for erythropoietin (EPO), glycolytic enzymes, and vascular endothelial growth factor (VEGF), enabling the cell to adapt to conditions of low oxygen. ${ }^{7,9,10}$

There is substantial evidence supporting the proposal that the $20 G$ oxygenases act via a consensus mechanism involving 2-electron oxidation of $2 \mathrm{OG}$ to form an $\mathrm{Fe}^{4+}$-oxo intermediate, followed by oxidation of the primary substrate (Figure S1). ${ }^{11}$ The 2OG oxygenases have a catalytic requirement for molecular oxygen, which has prompted kinetic analyses of this co-substrate for some members of the superfamily. The collagen prolyl hydroxylase $\mathrm{CP} 4 \mathrm{H}$ and the plant phytanoylCoA hydroxylase mPAHX have relatively low $K_{\mathrm{M}}{ }^{\text {app }}\left(\mathrm{O}_{2}\right)$ values of 40 and $93 \mu \mathrm{M}$, respectively, ${ }^{12,13}$ suggesting a low degree of sensitivity to oxygen availability in vitro. In contrast, PHD2 activity is highly sensitive to $\mathrm{O}_{2}$ availability, with reported $K_{\mathrm{M}}{ }^{\text {app }}\left(\mathrm{O}_{2}\right)$, values ranging between 230 and $1746 \mu \mathrm{M}^{12-15}$ and a slow reaction with oxygen in pre-steady state kinetic experiments. ${ }^{15}$ These features, along with the rapid degradation of HIF, are proposed to underlie its importance as a cellular oxygen sensor. FIH has a $K_{M}{ }^{\text {app }}\left(\mathrm{O}_{2}\right)$ of $110 \mu \mathrm{M},{ }^{16}$ implying a reduced dependence on oxygen availability and thus a potentially less significant role in oxygen sensing. Cellular studies have also demonstrated that PHD2-catalyzed HIF prolyl hydroxylation is reduced to a greater degree upon reduction of oxygen availability than HIF asparaginyl hydroxylation catalyzed by $\mathrm{FIH}^{17}$ Taken together, these results indicate that, although all 2OG oxygenases use oxygen as a co-substrate, the sensitivity of their activity with respect to oxygen concentration varies widely across the superfamily. This raises the question as to whether other members of the 2OG oxygenase superfamily may also have an "oxygen-sensing" capacity or whether the HIF hydroxylases, and particularly PHD2, are uniquely sensitive to changes in oxygen availability.

JmjC-KDM levels and activity have been reported to be influenced by hypoxia, as has histone methylation status. Our recent biochemical analysis of KDM4E revealed that its activity displays a graded response to oxygen over a physiologically relevant range of oxygen concentrations $(0-21 \%) .{ }^{18}$ Additionally, a range of $K_{M}{ }^{\text {app }}\left(\mathrm{O}_{2}\right)$ values for members of the KDM4 subfamily has been reported. ${ }^{19}$ Some JmjC-KDMs are known to be HIF target genes and upregulated in hypoxia in various cell lines (KDM3A, KDM4B, KDM4C, KDM5B, KDM5C, and $K D M 6 B),{ }^{20-26}$ while under hypoxia, KDM3A and KDM4C have been found to interact or cooperate with HIF at gene promoters and enhance the induction of HIF target genes in HCT116 and HeLa cell lines, respectively. ${ }^{27,28}$ Ectopically expressed KDM4B demonstrated a loss of cellular demethylase activity in HeLa cells incubated in hypoxia $\left(0.2 \% \mathrm{O}_{2}\right)$, whereas minimal effects on the activity of KDM3A were observed, suggesting differential oxygen sensitivity within the HIFregulated JmjC-KDMs. ${ }^{21}$ Furthermore, hypoxia has been found to induce changes to global (and, in some cases, genespecific) histone lysine methylation status in numerous cell lines, with consequent changes to gene expression profiles. $^{23,29-32}$ While the impact of hypoxia on chromatin structure is not well-understood, hypoxia in combination with nutrient depletion was shown to result in chromatin compaction, ${ }^{33}$ and the potential role of chromatin as an oxygen sensor has been postulated. ${ }^{34}$

These studies on the oxygen-dependence of JmjC-KDMs and global changes in histone lysine methylation status in hypoxic cells and tissues suggest that the activity of the JmjCKDMs may be differentially modulated by oxygen availability. This led us to investigate the effect of a range of oxygen concentrations on the activity of KDM4A to assess whether this enzyme has the capacity to function as an oxygen sensor, both kinetically and in a cellular context. KDM4A was chosen for investigation as it has been implicated in numerous hypoxic disease states, including breast, prostate, and lung cancers, ${ }^{35}$ and cardiac hypertrophy, ${ }^{36}$ and is a close homologue of KDM4E. Here, we report that the activity of both recombinant KDM4A and KDM4A overexpressed in cells displays sensitivity over physiologically relevant oxygen concentrations. This reveals the potential for the JmjC-KDMs to play a key role in fine-tuning transcriptional regulation in an oxygen-dependent manner.

\section{RESULTS AND DISCUSSION}

Dependence of KDM4A Activity on Oxygen Availability in Vitro. We initially assessed the sensitivity of isolated KDM4A demethylase activity at different oxygen concentrations by evaluating the $K_{\mathrm{M}}{ }^{\mathrm{app}}\left(\mathrm{O}_{2}\right)$ of recombinant $\mathrm{KDM}_{4-359}$, which comprises the Jumonji- $N$ and Jumonji- $C$ domains required for catalytic activity. ${ }^{37}$ As a prelude, steadystate kinetic analysis of $\mathrm{KDM}_{4} \mathrm{~A}_{1-359}$ with respect to $2 \mathrm{OG}$ and a 15 mer histone peptide substrate $\mathrm{H} 3_{1-15} \mathrm{~K} 9 \mathrm{me} 3^{38}$ was first conducted using a matrix assisted laser desorption / ionization time-of-flight mass spectrometry (MALDI-TOF-MS) assay. $K_{\mathrm{M}}{ }^{\text {app }}$ values of $24.7 \pm 6.7$ and $23.2 \pm 4.3 \mu \mathrm{M}$ for $2 \mathrm{OG}$ and $\mathrm{H} 3_{1-15} \mathrm{~K} 9 \mathrm{me} 3$ peptide substrate, respectively, were determined (Figure $1 \mathrm{a}, \mathrm{b}$ ) and found to be consistent with reported $K_{\mathrm{M}}{ }^{\text {app }}$ values obtained using other assay methods. ${ }^{38,39}$ We were then able to determine excess peptide and 2OG cosubstrate concentrations (200 and $100 \mu \mathrm{M}$, respectively) for use in the oxygen dependence assay to ensure saturating conditions of substrate and cosubstrate.

We then investigated the oxygen dependence of the reaction of $\mathrm{KDM}_{4} \mathrm{~A}_{1-359}$ with $\mathrm{H} 3_{1-15} \mathrm{~K} 9 \mathrm{me} 3$ peptide using a method described previously. ${ }^{15}$ Briefly, a mass flow controller (MFC, Brooks Instruments) was used to regulate the proportion of $\mathrm{O}_{2}$ and $\mathrm{N}_{2}$ used to purge sealed glass vials in which the reaction was performed. Analysis of the initial rate of reaction at oxygen concentrations between 0 and $80 \%(0-722 \mu \mathrm{M}$ Figure $\mathrm{S} 2)$ yielded a $K_{\mathrm{M}}{ }^{\text {app }}\left(\mathrm{O}_{2}\right)$ of $173 \pm 23 \mu \mathrm{M}$ for $\mathrm{KDM}_{4} \mathrm{~A}_{1-359}$ (Figure 1c). This value lies between reported $K_{\mathrm{M}}{ }^{\text {app }}\left(\mathrm{O}_{2}\right)$ values of the HIF hydroxylases $\mathrm{FIH}$ and PHD2, as determined using the same assay $(110 \text { and }>450 \mu \mathrm{M} \text {, respectively })^{15,16}$ and is significantly higher than reported values for other $2 \mathrm{OG}$ oxygenases. ${ }^{12,13,32}$ This suggests that KDM4A activity may be responsive to changes in a physiologically relevant range of oxygen concentrations, thereby possessing the biochemical potential to act as an oxygen sensor.

Loss of H3K9me3 in Cells Overexpressing KDM4A is Dependent on Oxygen Availability. Given that the differences in the in vitro oxygen sensitivity of the HIF hydroxylases ${ }^{15,16}$ appeared to correlate with their $\mathrm{O}_{2}$ sensitivities in cells, ${ }^{17}$ we next investigated the effect of hypoxia on the cellular activity of KDM4A to establish whether a similar relationship between the in vitro and cellular oxygen dependence of the enzyme was apparent. Furthermore, some previous biochemical studies have reported $K_{\mathrm{M}}\left(\mathrm{O}_{2}\right)$ values that vary with 
a

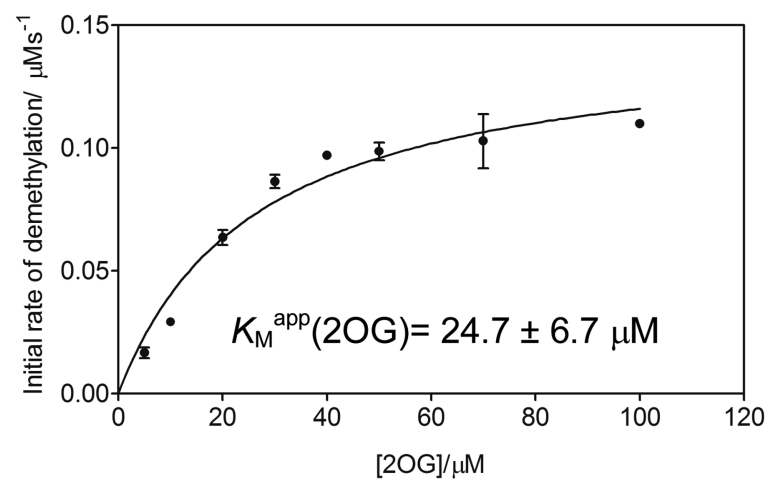

b

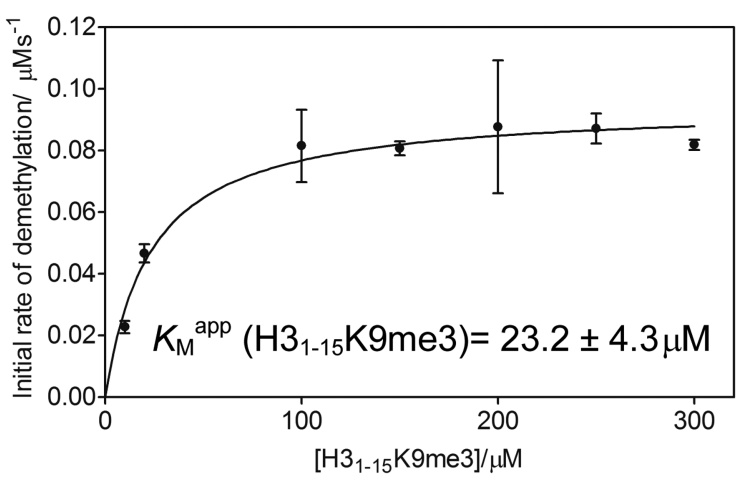

C

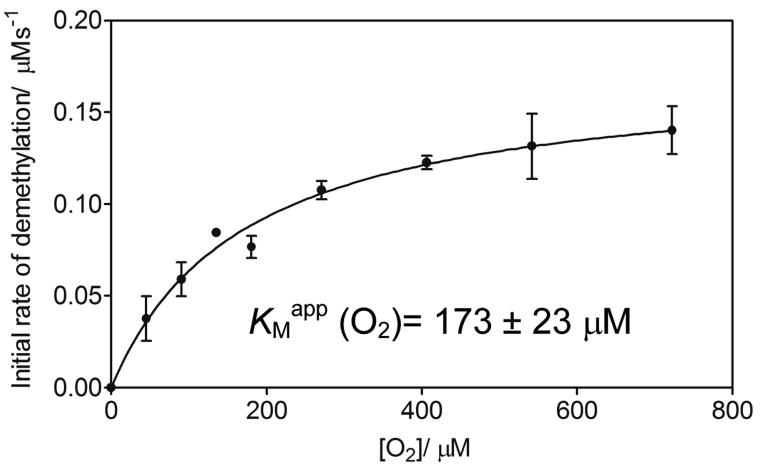

Figure 1. Kinetic analysis of recombinant $\mathrm{KDM}_{4} \mathrm{~A}_{1-359}$ using a MALDI-TOF-MS-based assay. $K_{\mathrm{M}}^{\text {app }}$ values for (a) $20 \mathrm{OG}$ and (b) $\mathrm{H} 3_{1-15} \mathrm{~K} 9 \mathrm{me} 3$ for $\mathrm{KDM}_{4} \mathrm{~A}_{1-359}$ were initially determined. (c) Steady-state determination of $\mathrm{KDM}_{4} \mathrm{~A}_{1-359}$ kinetics with respect to oxygen revealed a $K_{\mathrm{M}}^{\mathrm{app}}\left(\mathrm{O}_{2}\right)$ of $173 \pm 23 \mu \mathrm{M}$. An approximately 5-10 fold excess of $K_{\mathrm{M}}$ app $2 \mathrm{OG}$ and $\mathrm{H}_{1-15} \mathrm{~K} 9 \mathrm{me} 3$ peptide was used to ensure saturating conditions of all (co)substrates at $37^{\circ} \mathrm{C}$. GraphPad Prism was used to fit data to a Michaelis-Menten model and evaluate kinetic parameters. A total of three biological repeats using different preparations of $\mathrm{KDM}_{4} \mathrm{~A}_{1-359}$ with $n=3$ technical repeats were performed; error bars denote standard deviation (sd).

peptide length; ${ }^{13}$ hence, it was important to assess the oxygen dependence of the enzyme against its endogenous substrate. HeLa cells were transiently transfected with full-length wildtype (WT) N-terminally FLAG-tagged KDM4A or the inactive variant KDM4A H188A ${ }^{2}$ (MUT) and incubated in either 1 or $21 \% \mathrm{O}_{2}$ for $24 \mathrm{~h}$. Cells were stained for immunofluorescence analysis of FLAG and H3K9me3 levels, with 4',6-diamidino-2phenylindole (DAPI) staining verifying that ectopically expressed KDM4A was located in the nucleus (Figure $2 a-d$ ). Nuclear FLAG fluorescence signal was used to select a population of highly transfected cells whose $\mathrm{H} 3 \mathrm{~K} 9 \mathrm{me} 3$ levels were then quantified (Figure 2e). Similar expression of both WT and MUT enzymes was observed (Figure 2f). As expected, MUT-transfected cells displayed no changes in $\mathrm{H} 3 \mathrm{~K} 9 \mathrm{me} 3$ levels compared to untransfected cells in either normoxia or hypoxia (Figure 2b,d). To quantify loss of H3K9me3 in WT-transfected cells, average H3K9me3 fluorescence signal (RFU) was normalized against that in MUT-transfected cells incubated at the same oxygen concentration (Figure S4). In normoxia, the cells overexpressing WT KDM4A showed a pronounced decrease of $55 \pm 11 \%$ in $\mathrm{H} 3 \mathrm{~K} 9 \mathrm{me} 3$ staining relative to $\mathrm{H} 3 \mathrm{~K} 9 \mathrm{me} 3$ fluorescence in MUTtransfected cells, indicating demethylase activity (Figure 2a, b). In hypoxia, KDM4A WT-transfected cells retained significantly higher levels of $\mathrm{H} 3 \mathrm{~K} 9 \mathrm{me} 3$ compared with normoxic cells (Figure $2 \mathrm{a}, \mathrm{c}$ ) with a percentage loss of $33 \pm 11 \%$ relative to the MUT control. This was attributed to an approximately $40 \%$ reduction in KDM4A activity at $1 \%$ oxygen relative to that at $21 \%$ oxygen $(P \leq 0.05$, Figure $2 \mathrm{e})$, suggesting that cellular KDM4A catalytic activity is sensitive to reduction in oxygen availability.

Cellular KDM4A Activity Demonstrates a Graded Response to Hypoxia. We next assessed the cellular KDM4A demethylase activity across a range of physiologically relevant oxygen concentrations to ascertain its sensitivity to cellular oxygen availability. To facilitate this and to test whether KDM4A activity can also be modulated by hypoxia in a different cell line, a U2OS cell line stably expressing doxycycline-inducible FLAG-tagged WT KDM4A (full length) (herein termed U2OS F-KDM4A cells) was used (Figure S3).

Doxycycline hyclate was added to U2OS F-KDM4A cells, which were subsequently incubated at $0.1,1,5$ and $21 \% \mathrm{O}_{2}$, for $24 \mathrm{~h}$. Cells were then fixed and stained for FLAG and H3K9me3 (Figure 3a-d). At each oxygen concentration, global $\mathrm{H} 3 \mathrm{~K} 9 \mathrm{me} 3$ levels were normalized to those in uninduced U2OS F-KDM4A cells incubated under the same conditions to account for endogenous responses of the mark to hypoxia. Loss of H3K9me3 fluorescence in induced cells was then used to calculate percentage demethylation of this mark by the overexpressed KDM4A and correlated with KDM4A activity (Figure 3e; for calculations, see Figure S4). The percentage loss of $\mathrm{H} 3 \mathrm{~K} 9 \mathrm{me} 3$ in $\mathrm{KDM} 4 \mathrm{~A}$ induced U2OS cells at $1 \% \mathrm{O}_{2}$ was relatively consistent with loss of $\mathrm{H} 3 \mathrm{~K} 9 \mathrm{me} 3$ found in HeLa cells transiently transfected with KDM4A ( $50 \pm 5 \%$ compared with $\sim 40 \%$, respectively), indicating a similar effect of hypoxia on KDM4A activity in different cell lines. Overall, the data revealed a relative decrease in the demethylation of $\mathrm{H} 3 \mathrm{~K} 9 \mathrm{me} 3$ consistent with a graded loss of KDM4A activity with decreasing oxygen concentration. As expected, HIF- $1 \alpha$ stabilization was also observed for cells incubated at reduced oxygen concentrations $\left(0.1-5.0 \% \mathrm{O}_{2}\right)$ by Western blot analysis (Figure $3 \mathrm{f}(\mathrm{i})$ ).

Interestingly, we also observed an increase in KDM4A at the protein level with decreasing oxygen concentration in U2OS F-KDM4A cells (Figure 3f(ii),g) independent of changes at the transcript level (Figure 3h), suggesting that our analysis from immunofluorescence experiments may be underestimating the effect of hypoxia on loss of KDM4A activity because of increased FLAG-KDM4A expression. This increase in KDM4A protein is consistent with a recent study by Black et al, who observed a reduction of KDM4A activity against $\mathrm{H} 3 \mathrm{~K} 9 \mathrm{me} 3$ in $\mathrm{RPE}$ cells exposed to $1 \% \mathrm{O}_{2}$ for $24 \mathrm{~h}^{40}$ However, although chemical inhibition of JmjC-KDM activity abrogated KDM4A-mediated transient site-specific copy gain in hypoxia, hypoxic loss of activity did not have the same effect, ${ }^{40}$ suggesting that the downstream physiological effects of hypoxia on KDM4A function are somewhat subtle. Previous studies have revealed that stabilization of KDM4A in hypoxia is due to reduced interaction 

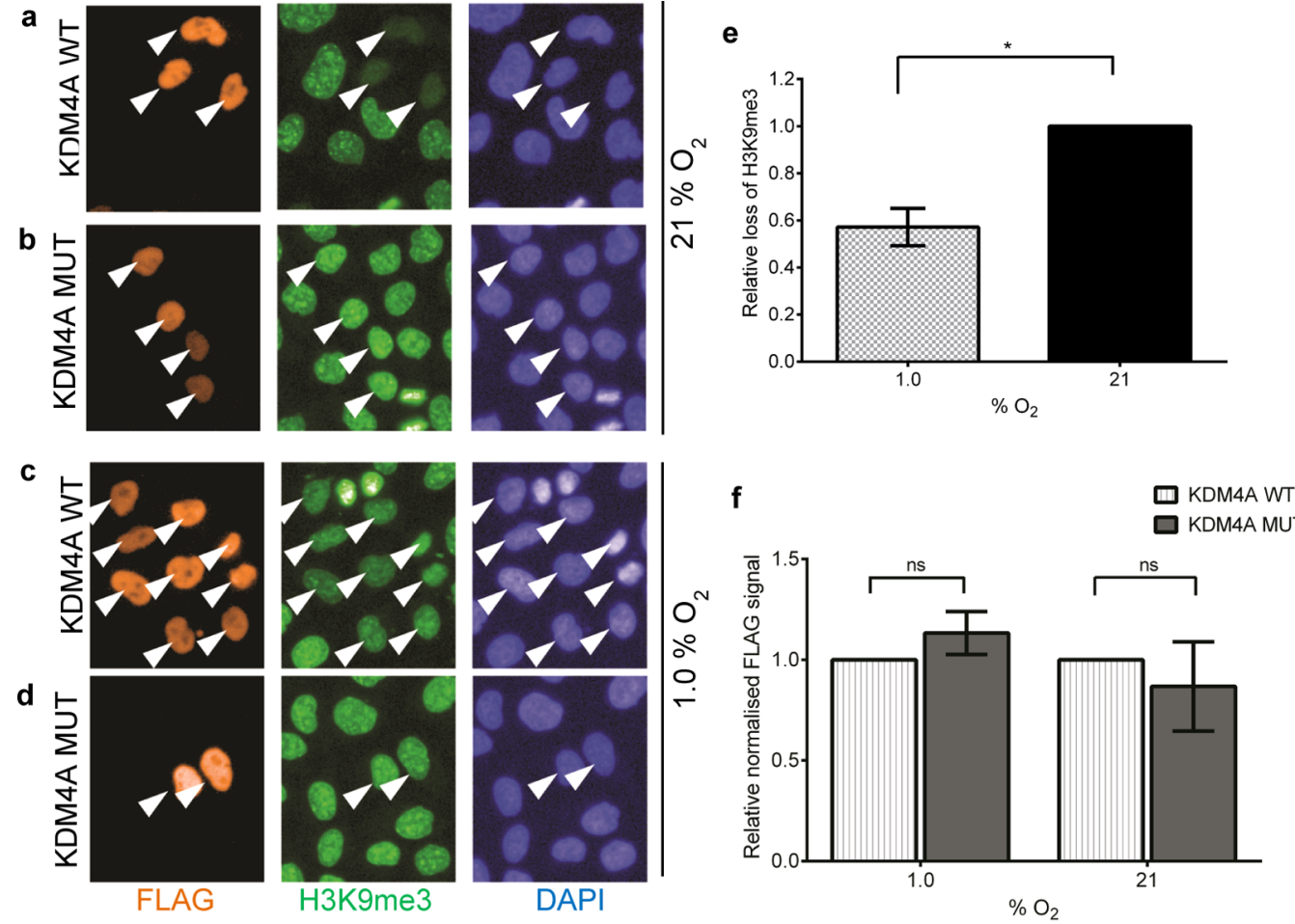

$$
50 \mu \mathrm{m}
$$

Figure 2. Hypoxia-dependent alteration of H3K9me3 levels in HeLa cells overexpressing FLAG-KDM4A. (a-d) Selected images from immunofluorescence analysis of the effect of hypoxia on the cellular activity of KDM4A. HeLa cells were transiently transfected with FLAG-tagged full length $\operatorname{KDM} 4 A$ WT $(a, c)$ or catalytically inactive KDM4A MUT $(b, d)$ and then incubated for $24 \mathrm{~h}$ at $21 \%(a, b)$ or $1 \% \mathrm{O}_{2}(\mathrm{c}, \mathrm{d})$. Images were processed and analyzed at the same time using the same fluorescence intensity signal window. (e) Calculation of relative loss of $\mathrm{H} 3 \mathrm{~K} 9 \mathrm{me} 3$ in normoxia $\left(21 \% \mathrm{O}_{2}\right)$ and hypoxia $\left(1.0 \% \mathrm{O}_{2}\right)$ reveals an approximately $40 \%$ reduction in hypoxia. Error bars denote sd; $N=3$; a paired $t$ test was performed using GraphPad Prism; $P \leq 0.05$. For the calculation method, see Figure S4. (f) Expression of transiently expressed FLAG-tagged KDM4A WT and KDM4A MUT is comparable in normoxia and hypoxia. Average FLAG fluorescence signal in KDM4A MUT-overexpressing cells was normalized against that in KDM4A WT-overexpressing cells in the cell populations selected for analysis $(n>50$ cells). No significant differences in FLAG signal were apparent. Error bars denote sd; $N=3$; two-way ANOVA was performed using GraphPad Prism; $P \leq 0.05$.

of the enzyme with the SKP1-Cul1-F-box ubiquitin ligase responsible for regulation of KDM4A turnover by the proteasome. ${ }^{41}$ Given the reduced catalytic activity of KDM4A in hypoxia, this stabilization may be a compensatory mechanism, as has been suggested regarding the HIF-induced upregulation of KDM4 isoforms KDM4B and KDM4C. ${ }^{21,22}$ Indeed, hypoxic stabilization of KDM4A has been shown to increase its association with chromatin, ${ }^{41}$ thereby potentially ameliorating the effects of hypoxia on its catalytic activity and rationalizing the different effects observed upon chemical and hypoxic inhibition of $\mathrm{KDM}_{4 \mathrm{~A}}{ }^{40}$ Although the biological implications of the observed oxygen sensitivity are yet to be elucidated, our experiments in U2OS F-KDM4A cells suggest that both KDM4A activity and protein levels can be "tuned" in varying degrees of hypoxia, which may be further indication of an oxygen sensing role for KDM4A.

Quantitative Western blots were performed to assess the effect of hypoxia on KDM4A activity against multiple methylated lysine marks (H3K9me3, H3K36me3, H3K27me3, and $\mathrm{H} 3 \mathrm{~K} 4 \mathrm{me} 3$ ) in total populations of both induced and uninduced U2OS F-KDM4A cells as well as a control parental U2OS cell line (U2OS (P), Figure S3). Multiplexed fluorescent analysis allowed levels of these methylation marks to be normalized against a simultaneously quantified $\mathrm{H} 3$ loading control for each sample (Figure 4a). Normalized values from induced samples were then compared to those in uninduced samples incubated at the same concentration of $\mathrm{O}_{2}$, and the relative loss of methylation due to overexpression of KDM4A in each condition was calculated. The Western blots confirmed that induction of KDM4A overexpression led to a significant decrease in $\mathrm{H} 3 \mathrm{~K} 9 \mathrm{me} 3$ levels in normoxia (Figure $4 \mathrm{~b}(\mathrm{i})$ ). Moderate and graded reduction in $\mathrm{H} 3 \mathrm{~K} 9 \mathrm{me} 3$ levels and, to a lesser extent, H3K36me3 levels was observed in KDM4A overexpressing cells in hypoxia (Figure $4 \mathrm{~b}(\mathrm{ii})$ ), displaying a similar trend to that seen in immunofluorescence experiments. Although levels of the non-KDM4A-substrate H3K4me3 mark demonstrated no significant changes on overexpression of KDM4A (Figure 4b(iv)), interestingly, analysis of the H3K27me3 mark showed loss of this mark upon overexpression of KDM4A in normoxia, with a graded response to oxygen (Figure $4 \mathrm{~b}(\mathrm{iii})$ ) similar to that seen for $\mathrm{H} 3 \mathrm{~K} 9 \mathrm{me} 3$, although less-pronounced. $\mathrm{H} 3 \mathrm{~K} 27 \mathrm{me} 3$ is not a canonical substrate for KDM4A, hence, loss of this mark cannot be directly attributed to catalytic KDM4A activity. However, KDM4A has been shown to be capable of catalyzing demethylation of a $\mathrm{H} 3 \mathrm{~K} 27 \mathrm{me} 3$ peptide substrate in vitro. ${ }^{42}$ It is also possible that global demethylation of $\mathrm{H} 3 \mathrm{~K} 9 \mathrm{me} 3$ and $\mathrm{H} 3 \mathrm{~K} 36 \mathrm{me} 3$ affects the H3K27me3 mark through alternative pathways. There is increasing evidence to suggest that the function, selectivity, and activity of individual JmjC-KDMs is affected by the presence or absence of 
a

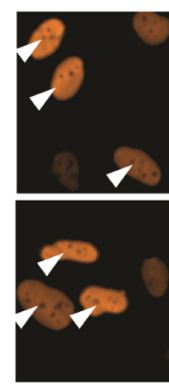

C

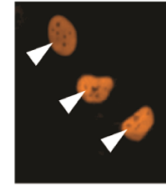

d

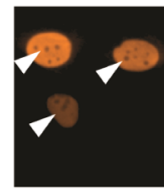

FLAG
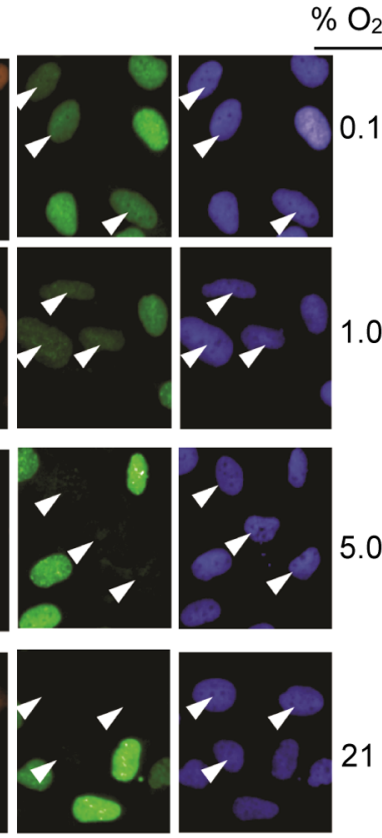

H3K9me3

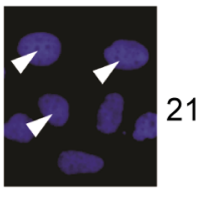

DAPI

$50 \mu \mathrm{m}$

e

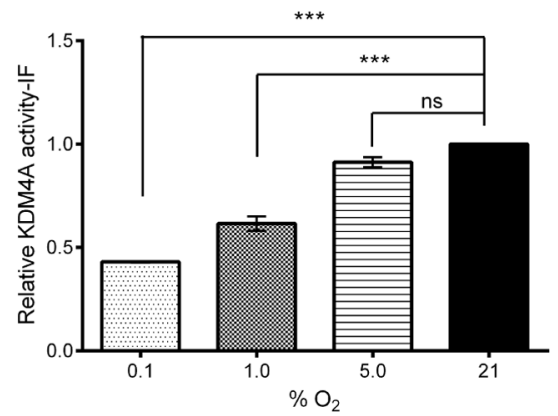

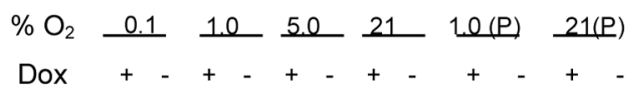

(i)
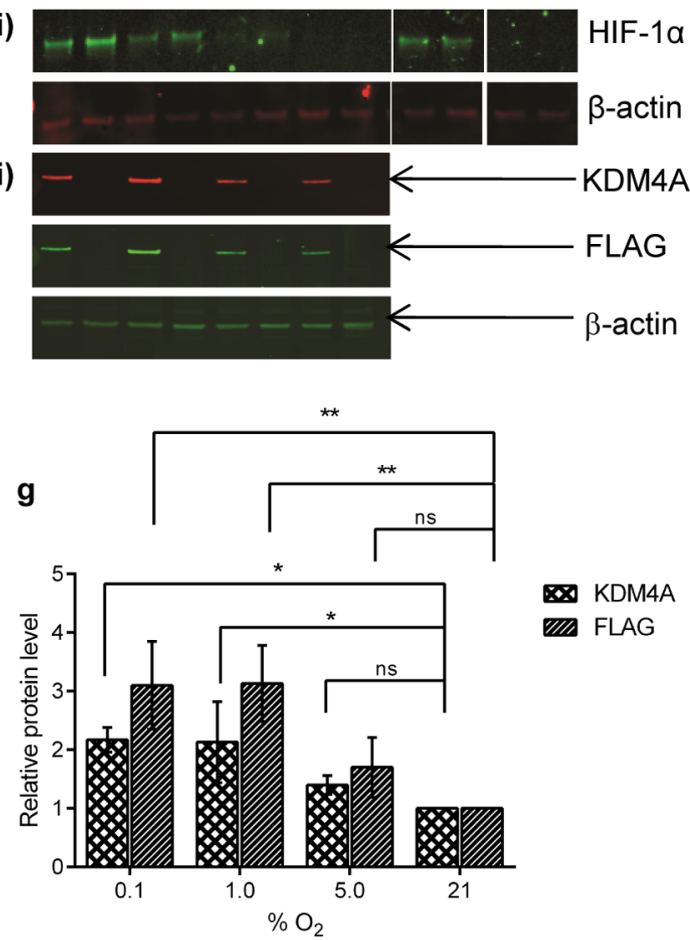

KDM4A

WII FLAG

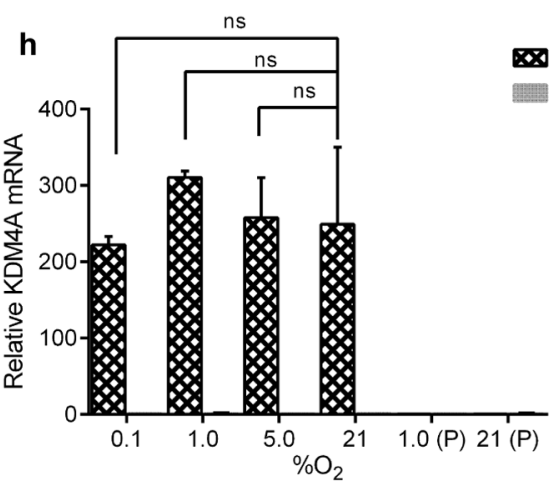

Figure 3. Cellular demethylase activity of KDM4A demonstrates a graded response to oxygen concentration in U2OS cells. (a-d). Representative images from immunofluorescence analysis of the oxygen sensitivity of cellular KDM4A. Doxycycline (Dox)-inducible U2OS stable cells were induced to overexpress FLAG-KDM4A WT and incubated at (a) $0.1 \%$, (b) $1.0 \%$, (c) $5.0 \%$, or (d) $21 \% \mathrm{O}_{2}$ for $24 \mathrm{~h}$. H3K9me3 signal in induced cells (indicated by arrows) was normalized against signal in uninduced cells and correlated to enzyme activity (Figure S4). (e) Cellular KDM4A H3K9me3 demethylase activity in $\mathrm{O}_{2}$ concentrations from 0.1 to $5.0 \%$ relative to $21 \%$. Quantification is based on three biological repeats; error bars denote sd. One-way ANOVA with Dunnett's multiple comparison test against the result for $21 \% \mathrm{O}_{2}$ was performed in GraphPad Prism. $N>50$ cells were used for each experiment; cells incubated in each oxygen concentration were processed, imaged, and analyzed simultaneously. (f)(i)Western blot analysis of cell lysates from induced and uninduced U2OS F-KDM4A and parental U2OS cells (P) reveals stabilization of HIF-1 $\alpha$ in cells incubated at 0.1$5.0 \% \mathrm{O}_{2}$ compared to cells incubated at $21 \% \mathrm{O}_{2} . \beta$-actin was used as a loading control. (ii) Multiplexed fluorescent Western blot (red, anti-KDM4A; green, anti- FLAG and anti-actin) and (g) quantitative graph showing levels of FLAG-KDM4A protein in U2OS F-KDM4A cells treated \pm dox and incubated at $0.1-21 \% \mathrm{O}_{2}$ for $24 \mathrm{~h}$. The membrane was stained simultaneously for KDM4A, FLAG, and $\beta$-actin to enable direct quantification and comparison. P denotes parental U2OS cells, which were used to control for dox-dependent effects. All signals were normalized to the $\beta$-actin loading control. Levels of overexpressed FLAG-KDM4A were quantified relative to those in normoxic cells treated with dox. Quantitation is based on three biological repeats; error bars denote sd and two-way ANOVA with Dunnett's multiple comparison test was performed using GraphPad Prism. (h) Hypoxia does not affect expression levels of KDM4A mRNA. Relative mRNA levels of KDM4A U2OS F-KDM4A cells \pm dox incubated for 24 h in $0.1 \%-21 \%$ oxygen, and U2OS parental cells $(\mathrm{P})$ incubated at 1.0 and $21 \% \mathrm{O}_{2}$, were analyzed by RT-qPCR. A two-way ANOVA with Dunnett's multiple comparison was performed using GraphPad Prism; error bars denote sd; $N=2$; control= -dox; and $21 \% \mathrm{O}_{2}$.

post-translational modifications distal to the mark upon which they are acting via disruption of necessary interactions with binding and reader domains; ${ }^{43,44}$ hence, aberrant demethylation of one lysine methylation mark may have an impact on others.
Aberrant histone lysine methylation and altered JmjC-KDM expression levels have been observed in hypoxic disease states such as cancer ${ }^{35}$ and cardiovascular diseases such as cardiomyopathy and cardiac hypertrophy. ${ }^{32,36,45}$ The potential 


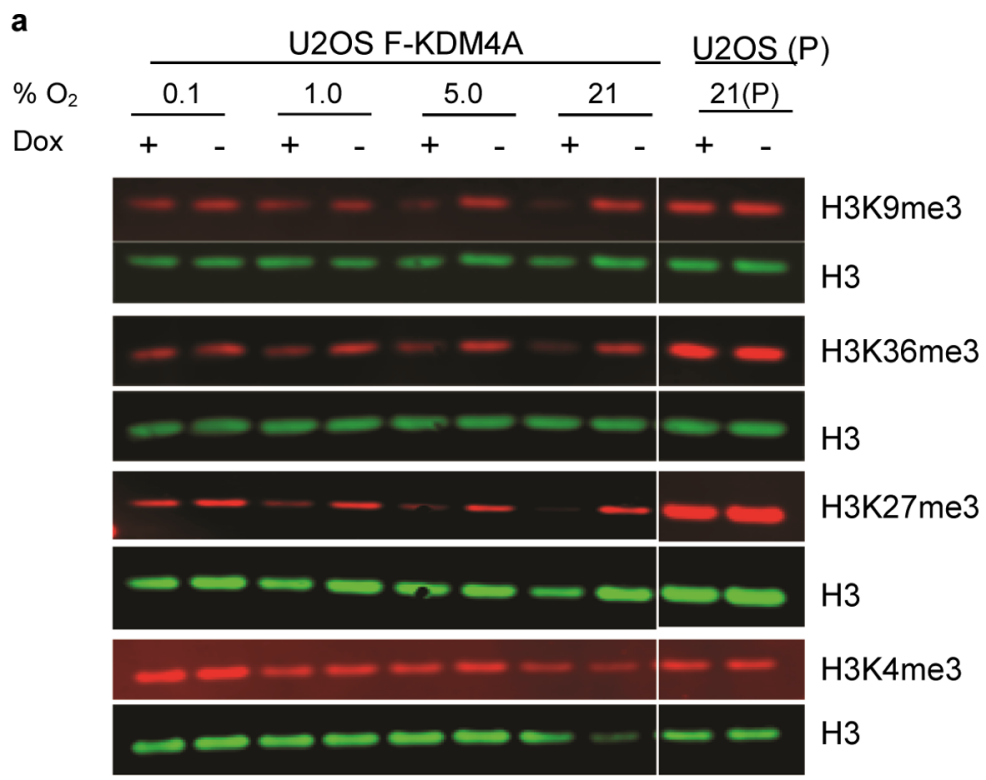

b
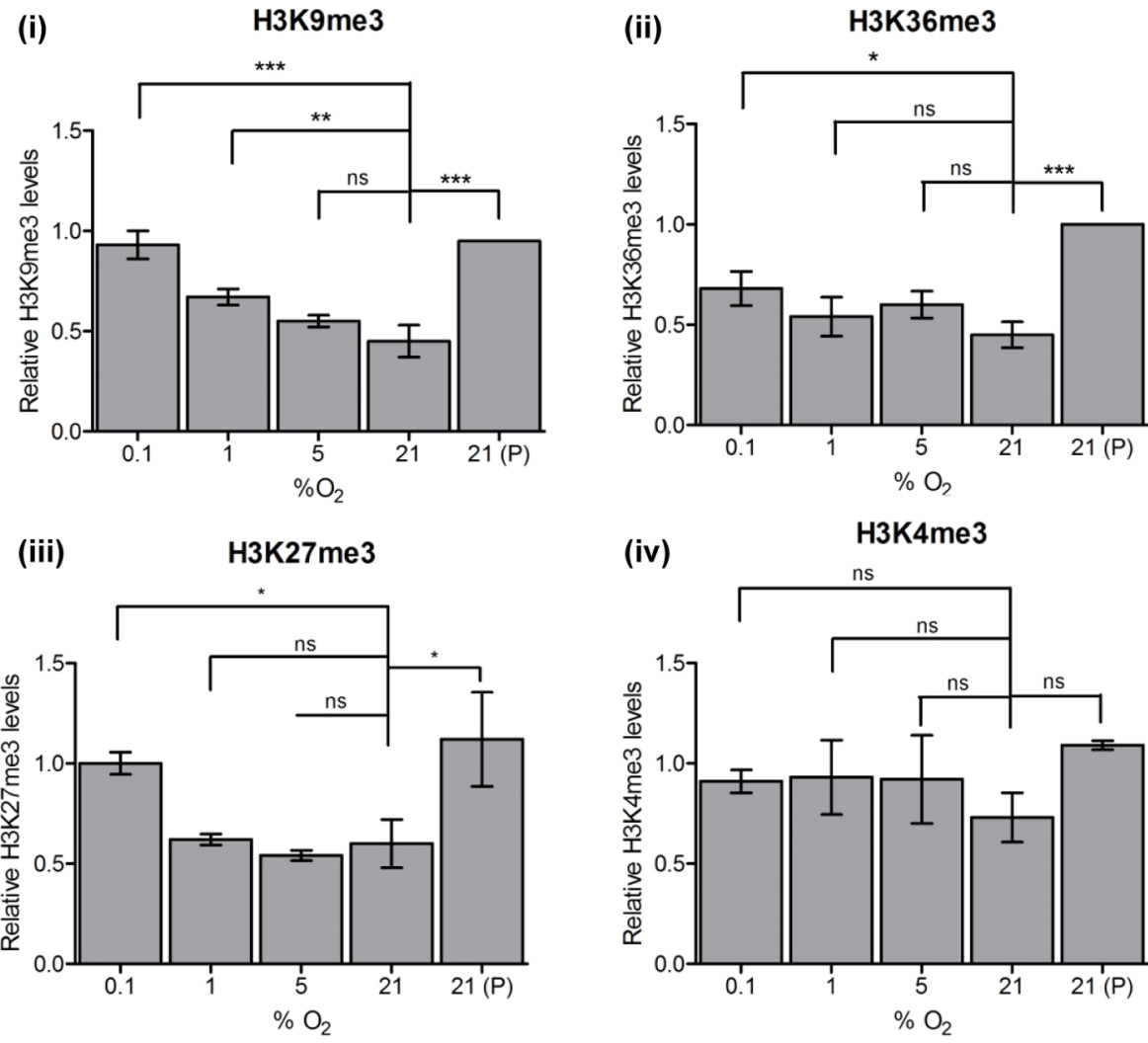

Figure 4. Alteration of multiple $\mathrm{H} 3$ methylation marks by KDM4A at different oxygen concentrations. (a) Fluorescent Western blots showing levels of $\mathrm{H} 3 \mathrm{~K} 9 \mathrm{me} 3, \mathrm{H} 3 \mathrm{~K} 36 \mathrm{me} 3$, and $\mathrm{H} 3 \mathrm{~K} 27 \mathrm{me} 3$ histone methylation marks in induced or uninduced U2OS F-KDM4A cells incubated at $0.1-21 \% \mathrm{O}_{2}$. P denotes parental U2OS cells. The membrane was stained simultaneously for H3K9me3, H3K36me3, H3K27me3, H3K4me3, and H3, with methylation marks being normalized against the signal for $\mathrm{H} 3$. Representative Western blots are shown and have been cropped to show only relevant molecular weights. Western blots were imaged using Odyssey CLx fluorescent imaging system (LI-COR) and analyzed using Image Studio software (LI-COR). (b) Graphs showing quantification of (i) H3K9me3, (ii) H3K36me3, (iii) H3K27me3, and (iv) H3K4me3 levels from Western blots. Levels of trimethylated lysine marks were normalized to $\mathrm{H} 3$ levels and then quantitated relative to those in uninduced cells incubated at the same $\mathrm{O}_{2}$ concentration to discount any non-KDM4A mediated effect in methylation changes. Error bars denote sd and one-way ANOVA with Dunnett's multiple comparison test was performed using GraphPad Prism; $N=3$.

involvement of the JmjC-KDMs in these hypoxic diseases highlights the importance of understanding the impact of hypoxia on their activity. Here, we demonstrate a link between the biochemical oxygen sensitivity of isolated KDM4A and the effect of cellular hypoxia on its catalytic activity, with a loss of KDM4A activity in hypoxia resulting in changes to global histone lysine methylation. A comparative study with which to assess the oxygen sensitivity of multiple demethylases using the 
methods described herein would further develop our understanding of the potential for differential oxygen sensitivity across the JmjC-KDMs, as has previously been observed both in cells ${ }^{21,46}$ and in vitro, particularly for the KDM4 subfamily. ${ }^{19}$ Overall, however, these results suggest that KDM4A possesses the potential to act as an oxygen sensor in the context of epigenetic regulation. While these observations are yet to be validated in an endogenous setting, importantly, they present a possible complementary mechanism to the HIF pathway for hypoxic regulation of gene expression.

\section{METHODS}

Recombinant KDM4A Assays. $\mathrm{N}$-terminally $\mathrm{His}_{6}$-tagged truncated $\mathrm{KDM}_{4} \mathrm{~A}_{1-359}$ was expressed in Escherichia coli BL21(DE3) cells and purified via nickel affinity followed by size-exclusion chromatography, as reported previously. ${ }^{37} \mathrm{H} 3_{1-15} \mathrm{~K} 9 \mathrm{me} 3$ peptide was synthesized using a Liberty Blue automated microwave peptide synthesizer (CEM) and purified via reverse-phase high-performance liquid chromatography (HPLC). Activity assays were performed using the following conditions: $1 \mu \mathrm{M} \mathrm{KDM}_{4 \mathrm{~A}_{1-359}}, 200 \mu \mathrm{M} \mathrm{H} 3_{1-15} \mathrm{~K} 9 \mathrm{me} 3,200 \mu \mathrm{M} 2 \mathrm{OG}$, $100 \mu \mathrm{M}$ L-ascorbate, and $10 \mu \mathrm{M} \mathrm{Fe}^{2+}$ in $50 \mathrm{mM}$ HEPES (pH 7.5). Experiments to determine $K_{\mathrm{M}}$ values of $\mathrm{H} 3_{1-15} \mathrm{~K} 9 \mathrm{me} 3$, 2OG, and $\mathrm{O}_{2}$ used these conditions but varied the concentration of the (co)substrate under investigation. For oxygen-dependence assays, the activity of $\mathrm{KDM}_{4} \mathrm{~A}_{1-359}$ was assessed at varied oxygen concentrations. Peptide and buffer $(94 \mu \mathrm{L})$ were equilibrated in septa-sealed glass vials for 5 min at $37^{\circ} \mathrm{C}$ using a mass flow controller (Brooks Instruments) to control the ratios of $\mathrm{O}_{2}$ to $\mathrm{N}_{2}$. Sequential addition of 2OG $(1 \mu \mathrm{L})$, L-ascorbate $(1 \mu \mathrm{L})$, and $\mathrm{Fe}^{2+}(2 \mu \mathrm{L})$ was followed by initiation of the enzymatic reaction by addition of $\mathrm{KDM}_{4-359}(1 \mu \mathrm{L})$ using gastight Hamilton syringes and incubation at $37^{\circ} \mathrm{C}$ for $5 \mathrm{~min}$. The reaction was quenched with $\mathrm{MeOH}$ in a $1: 1$ ratio and $1 \mu \mathrm{L}$ removed for analysis via MALDI-TOF-MS.

Stable Transfectants. The human KDM4A gene was cloned into a modified pUHD10-3 MCS vector to enable expression of an $\mathrm{N}$-terminally FLAG-tagged KDM4A protein. Stable transfectants were then generated from U2OS cells bearing the reverse tetracycline responsive transactivator ${ }^{47}$ and a tetKRAB silencer construct ${ }^{48}$ by transfection with the pUHD10 FLAG vector alone or pUHD10-FLAGKDM4A in combination with pSV2-hph (ratio 10:1) using FuGENE 6 (Roche Applied Science). A total of $24 \mathrm{~h}$ after transfection, cells were selected with hygromycin B $\left(150 \mu \mathrm{gml}^{-1}\right)$. Independent clones were picked, maintained in selection media (Dulbecco's modified Eagle's medium supplemented with $10 \%$ Tet system-approved fetal bovine serum (FBS, Clontech), penicillin G $\left(50 \mathrm{IU} \mathrm{mL}^{-1}\right)$, streptomycin $\left(50 \mu \mathrm{g} \mathrm{mL}^{-1}\right)$ (Invitrogen), L-glutamine $(2 \mathrm{mM})$ (Sigma), blasticidin $\mathrm{S}$ $\left(5 \mu \mathrm{g} \mathrm{mL}^{-1}\right)$ (Invitrogen), and hygromycin B $\left(150 \mu \mathrm{g} \mathrm{mL}^{-1}\right.$; Roche Applied Science)) and tested for doxycycline-inducible gene expression (Figure S2). Clone 1 was verified and used for experiments (Figure S3).

HeLa Cells. HeLa cells were maintained in DMEM media supplemented with $10 \% \mathrm{FBS}$ and 5\% L-glutamine and incubated at $37{ }^{\circ} \mathrm{C}, 5 \% \mathrm{CO}_{2}$, and the required $\mathrm{O}_{2}$ concentration. Cells were transfected with pCDNA3 encoding full length, $N$-terminally FLAG-tagged KDM4A or KDM4A H188A variant using FuGENE HD transfection reagent (Promega) according to the manufacturer's protocol. For immunofluorescence experiments, after $4 \mathrm{~h}$, the media on the cells was changed and the cells transferred to the relevant experimental conditions.

U2OS FLAG-KDM4A Cells. U2OS FLAG-KDM4A cells were maintained in selection media throughout experiments and incubated at $37{ }^{\circ} \mathrm{C}, 5 \% \mathrm{CO}_{2}$ and the required $\mathrm{O}_{2}$ concentration. Cells were dosed with doxycycline $\left(1 \mu \mathrm{g} \mathrm{mL}^{-1}\right)$ or left untreated and then transferred immediately to relevant experimental conditions.

Hypoxic Cellular Experiments. Hypoxic incubations of cells were performed in an Invivo2 400 hypoxic workstation (Ruskinn Technologies). All $\mathrm{O}_{2}$ gradient assays were performed simultaneously in hypoxic chambers set at $0.1,1.0$ and $5.0 \% \mathrm{O}_{2}$, with normoxic cells maintained at $21 \% \quad \mathrm{O}_{2}$. For immunofluorescence experiments and Western blots of histone marks, cells were removed from the hypoxic stations prior to fixing or scraping, respectively. For HIF Western blots, cells were scraped in the hypoxic workstations.

Immunofluorescence. A protocol adapted from King et al, $2010^{49}$ was used for immunofluorescence assays. Briefly, after $24 \mathrm{~h}$ of incubation at the required oxygen concentration, cells were fixed, permeabilized and stained for FLAG and H3K9me3 (see Table S1 for a list of antibodies) and DAPI (Sigma D9564) to stain DNA. Goat anti-rabbit secondary antibody conjugated to Alexa Fluor 488 (Life Technologies A11034) and goat anti-mouse secondary antibody conjugated to Alexa Fluor 594 (Life Technologies A11032) were used to fluorescently label the FLAG and H3K9me3 primary antibodies. All fixing and staining procedures were performed simultaneously for each biological experiment. Image acquisition was performed using an Operetta high content imaging system (PerkinElmer), and images were analyzed using Harmony high content imaging and analysis software (PerkinElmer). Cell nuclei were automatically identified by DAPI staining using the default parameters. Cells overexpressing high amounts of KDM4A, where FLAG-tag staining was bright, were selected for analysis of $\mathrm{H} 3 \mathrm{~K} 9$ me 3 levels. In HeLa cells, H3K9me3 levels were normalized against those in cells transfected with the catalytically inactive KDM4A variant, which was deemed to possess $0 \%$ activity, while in U2OS FLAG-KDM4A cells, uninduced cells were used for normalization.

Western Blots. Following hypoxic or normoxic incubation, cells were scraped on ice in SDS-urea buffer $(6.7 \mathrm{M}$ urea, $10 \mathrm{mM}$ Tris-Cl $(\mathrm{pH} 6.8), 10 \% \mathrm{v} / \mathrm{v}$ glycerol, and $1 \% \mathrm{w} / \mathrm{v}$ SDS supplemented with 1 $\mathrm{mM}$ dithiothreitol and Complete Protease Inhibitor mixture (Roche Applied Science)). Lysates were then sonicated on ice for $10 \mathrm{~s}$ three times with a $10 \mathrm{~s}$ pause between cycles and snap-frozen at $-80{ }^{\circ} \mathrm{C}$. Total protein concentration was determined using a Pierce BCA assay kit (Thermo Scientific). Protein ( $1 \mu \mathrm{g}$ total per well) was loaded on a NuPage 4-12\% Bis-Tris gel (Life Technologies) and then transferred to a $0.45 \mu \mathrm{m}$ nitrocellulose membrane using wet transfer at $30 \mathrm{~V}$ for $1 \mathrm{~h}$. Membranes were blocked in SEA BLOCK blocking buffer (Thermo Scientific) overnight then probed with primary and fluorescent secondary antibodies (see Table S1) diluted in 3\% SEABLOCK, PBS, and 0.1\% Tween-20. Blots were imaged on an Odyssey CLx Fluorescent Imaging System (LI-COR) and analyzed using Image Studio software (LI-COR).

qPCR. RNA was isolated and purified from cells using the mirVana miRNA isolation kit (Life Technologies) according to the manufacturer's protocol. Isolated RNA was then treated with DNase using a Turbo DNA-free kit (Invitrogen) to remove DNA before reverse transcription using a High-Capacity cDNA Reverse Transcription kit (Applied Biosystems). A total of $1.5625 \mathrm{ng}$ of cDNA was submitted to qPCR analysis using $300 \mathrm{nM}$ primers (Sigma; see Table S2 for primer sequences) and Power SYBR Green Master Mix (Applied Biosystems) according to the manufacturer's protocol in a CFX1000 Thermal Cycler with a CFX96 Real-Time System (Bio-Rad). Data was collected and processed using CFX Manager Software v3.1 (Bio-Rad) and analyzed using the $\Delta \mathrm{Ct}$ method.

\section{ASSOCIATED CONTENT}

\section{Supporting Information}

The Supporting Information is available free of charge on the ACS Publications website at DOI: 10.1021/acschembio.6b00958.

Figures showing a consensus mechanism, in vitro $\mathrm{O}_{2}$ calibration, validation of the U2OS F-KDM4A cell line, and calculation of KDM4A activity. Tables showing antibodies used in immunofluorescence and Western blot experiments and sequences of primers. (PDF)

\section{AUTHOR INFORMATION}

\section{Corresponding Authors}

*E-mail: emily.flashman@chem.ox.ac.uk.

*E-mail: akane.kawamura@chem.ox.ac.uk.

ORCID

Akane Kawamura: 0000-0003-1169-5082 


\section{Author Contributions}

R.L.H. optimized and performed all in vitro and cellular experiments, analyzed the data, and wrote the manuscript. N.M. produced and validated stable U2OS cells, discussed the results, and commented on the manuscript. K.D. aided with optimization of the immunofluorescence experiments. E.F. and A.K. designed the study, discussed the results, and commented on the manuscript.

\section{Notes}

The authors declare no competing financial interest.

\section{ACKNOWLEDGMENTS}

The authors thank C. J. Schofield for valuable discussions, P. J. Ratcliffe for helpful suggestions on experimental design and $\mathrm{Mr}$ Ben Greenfield for establishing and calibrating the MFC assay. R.L.H., K.D., and A.K. acknowledge support from the BHF Centre of Research Excellence, Oxford (RE/08/004/23915). A.K. and E.F. are supported by Royal Society Dorothy Hodgkin Fellowships. This work was supported by the Engineering and Physical Sciences Research Council and Cancer Research UK (C8717/A18245).

\section{REFERENCES}

(1) Kouzarides, T. (2007) Chromatin modifications and their function. Cell 128, 693-705.

(2) Klose, R. J., Yamane, K., Bae, Y., Zhang, D., Erdjument-Bromage, H., Tempst, P., Wong, J., and Zhang, Y. (2006) The transcriptional repressor JHDM3A demethylates trimethyl histone $\mathrm{H} 3$ lysine 9 and lysine 36. Nature 442, 312-316.

(3) Trojer, P., Zhang, J., Yonezawa, M., Schmidt, A., Zheng, H., Jenuwein, T., and Reinberg, D. (2009) Dynamic Histone H1 Isotype 4 Methylation and Demethylation by Histone Lysine Methyltransferase G9a/KMT1C and the Jumonji Domain-containing JMJD2/KDM4 Proteins. J. Biol. Chem. 284, 8395-8405.

(4) Clifton, I. J., McDonough, M. A., Ehrismann, D., Kershaw, N. J., Granatino, N., and Schofield, C. J. (2006) Structural studies on 2oxoglutarate oxygenases and related double-stranded beta-helix fold proteins. J. Inorg. Biochem. 100, 644-669.

(5) Hausinger, R. P. (2008) $\mathrm{Fe}(\mathrm{II}) / \alpha$-Ketoglutarate-Dependent Hydroxylases and Related Enzymes. Crit. Rev. Biochem. Mol. Biol. 39 (1), 21-68.

(6) Semenza, G. L. (1998) Hypoxia-inducible factor 1: master regulator of $\mathrm{O} 2$ homeostasis. Curr. Opin. Genet. Dev. 8, 588-594.

(7) Schofield, C. J., and Ratcliffe, P. J. (2004) Oxygen sensing by HIF hydroxylases. Nat. Rev. Mol. Cell Biol. 5, 343-354.

(8) Myllyharju, J. (2013) Prolyl 4-hydroxylases, master regulators of the hypoxia response. Acta Physiol. 208, 148-165.

(9) Schödel, J., Mole, D. R., and Ratcliffe, P. J. (2013) Pan-genomic binding of hypoxia-inducible transcription factors. Biol. Chem. 394, 507-517.

(10) Semenza, G. L. (2014) Oxygen sensing, hypoxia-inducible factors, and disease pathophysiology. Annu. Rev. Pathol.: Mech. Dis. 9, $47-71$.

(11) Martinez, S., and Hausinger, R. P. (2015) Catalytic Mechanisms of $\mathrm{Fe}(\mathrm{II})$ - and 2-Oxoglutarate-dependent Oxygenases. J. Biol. Chem. 290, 20702-20711.

(12) Hirsilä, M., Koivunen, P., Günzler, V., Kivirikko, K. I., and Myllyharju, J. (2003) Characterization of the human prolyl 4hydroxylases that modify the hypoxia-inducible factor. J. Biol. Chem. 278, 30772-30780.

(13) Ehrismann, D., Flashman, E., Genn, D. N., Mathioudakis, N., Hewitson, K. S., Ratcliffe, P. J., and Schofield, C. J. (2007) Studies on the activity of the hypoxia-inducible-factor hydroxylases using an oxygen consumption assay. Biochem. J. 401, 227-234.

(14) Dao, J. H., Kurzeja, R. J. M., Morachis, J. M., Veith, H., Lewis, J., Yu, V., Tegley, C. M., and Tagari, P. (2009) Kinetic characterization and identification of a novel inhibitor of hypoxia-inducible factor prolyl hydroxylase 2 using a time-resolved fluorescence resonance energy transfer-based assay technology. Anal. Biochem. 384, 213-223.

(15) Tarhonskaya, H., Chowdhury, R., Leung, I. K. H., Loik, N. D., McCullagh, J. S. O., Claridge, T. D. W., Schofield, C. J., and Flashman, E. (2014) Investigating the contribution of the active site environment to the slow reaction of hypoxia-inducible factor prolyl hydroxylase domain 2 with oxygen. Biochem. J. 463, 363-372.

(16) Tarhonskaya, H., Hardy, A. P., Howe, E. A., Loik, N. D., Kramer, H. B., McCullagh, J. S. O., Schofield, C. J., and Flashman, E. (2015) Kinetic Investigations of the Role of Factor Inhibiting Hypoxia-inducible Factor (FIH) as an Oxygen Sensor. J. Biol. Chem. 290, 19726-19742.

(17) Tian, Y.-M., Yeoh, K. K., Lee, M. K., Eriksson, T., Kessler, B. M., Kramer, H. B., Edelmann, M. J., Willam, C., Pugh, C. W., Schofield, C. J., and Ratcliffe, P. J. (2011) Differential sensitivity of hypoxia inducible factor hydroxylation sites to hypoxia and hydroxylase inhibitors. J. Biol. Chem. 286, 13041-13051.

(18) Sanchez-Fernandez, E. M., Tarhonskaya, H., Al-Qahtani, K., Hopkinson, R. J., McCullagh, J. S., Schofield, C. J., and Flashman, E. (2013) Investigations on the oxygen dependence of a 2-oxoglutarate histone demethylase. Biochem. J. 449, 491-496.

(19) Cascella, B., and Mirica, L. M. (2012) Kinetic analysis of irondependent histone demethylases: $\alpha$-ketoglutarate substrate inhibition and potential relevance to the regulation of histone demethylation in cancer cells. Biochemistry 51, 8699-8701.

(20) Lee, H.-Y., Choi, K., Oh, H., Park, Y.-K., and Park, H. (2014) HIF-1-dependent induction of Jumonji domain-containing protein (JMJD) 3 under hypoxic conditions. Mol. Cells 37, 43-50.

(21) Beyer, S., Kristensen, M. M., Jensen, K. S., Johansen, J. V., and Staller, P. (2008) The histone demethylases JMJD1A and JMJD2B are transcriptional targets of hypoxia-inducible factor HIF. J. Biol. Chem. 283, 36542-36552.

(22) Pollard, P. J., Loenarz, C., Mole, D. R., McDonough, M. A., Gleadle, J. M., Schofield, C. J., and Ratcliffe, P. J. (2008) Regulation of Jumonji-domain-containing histone demethylases by hypoxia-inducible factor (HIF)-1alpha. Biochem. J. 416, 387-394.

(23) Xia, X., Lemieux, M. E., Li, W., Carroll, J. S., Brown, M., Liu, X. S., and Kung, A. L. (2009) Integrative analysis of HIF binding and transactivation reveals its role in maintaining histone methylation homeostasis. Proc. Natl. Acad. Sci. U. S. A. 106, 4260-4265.

(24) Wellmann, S., Bettkober, M., Zelmer, A., Seeger, K., Faigle, M., Eltzschig, H. K., and Bührer, C. (2008) Hypoxia upregulates the histone demethylase JMJD1A via HIF-1. Biochem. Biophys. Res. Commun. 372, 892-897.

(25) Niu, X., Zhang, T., Liao, L., Zhou, L., Lindner, D. J., Zhou, M., Rini, B., Yan, Q., and Yang, H. (2012) The von Hippel-Lindau tumor suppressor protein regulates gene expression and tumor growth through histone demethylase JARID1C. Oncogene 31, 776-786.

(26) Yang, J., Ledaki, I., Turley, H., Gatter, K. C., Montero, J.-C. M., Li, J.-L., and Harris, A. L. (2009) Role of hypoxia-inducible factors in epigenetic regulation via histone demethylases. Ann. N. Y. Acad. Sci. 1177, 185-197.

(27) Krieg, A. J., Rankin, E. B., Chan, D., Razorenova, O., Fernandez, S., and Giaccia, A. J. (2010) Regulation of the histone demethylase JMJD1A by hypoxia-inducible factor 1 alpha enhances hypoxic gene expression and tumor growth. Mol. Cell. Biol. 30, 344-353.

(28) Luo, W., Chang, R., Zhong, J., Pandey, A., and Semenza, G. L. (2012) Histone demethylase JMJD2C is a coactivator for hypoxiainducible factor 1 that is required for breast cancer progression. Proc. Natl. Acad. Sci. U. S. A. 109, E3367-3376.

(29) Tausendschön, M., Dehne, N., and Brüne, B. (2011) Hypoxia causes epigenetic gene regulation in macrophages by attenuating Jumonji histone demethylase activity. Cytokine+ 53, 256-262.

(30) Johnson, A. B., Denko, N., and Barton, M. C. (2008) Hypoxia induces a novel signature of chromatin modifications and global repression of transcription. Mutat. Res., Fundam. Mol. Mech. Mutagen. 640, 174-179. 
(31) Olcina, M. M., Foskolou, I. P., Anbalagan, S., Senra, J. M., Pires, I. M., Jiang, Y., Ryan, A. J., and Hammond, E. M. (2013) Replication stress and chromatin context link ATM activation to a role in DNA replication. Mol. Cell 52, 758-766.

(32) Hancock, R. L., Dunne, K., Walport, L. J., Flashman, E., and Kawamura, A. (2015) Epigenetic regulation by histone demethylases in hypoxia. Epigenomics 7, 791-811.

(33) Kirmes, I., Szczurek, A., Prakash, K., Charapitsa, I., Heiser, C., Musheev, M., Schock, F., Fornalczyk, K., Ma, D., Birk, U., Cremer, C., and Reid, G. (2015) A transient ischemic environment induces reversible compaction of chromatin. Genome Biol. 16, 246-265.

(34) Melvin, A., and Rocha, S. (2012) Chromatin as an oxygen sensor and active player in the hypoxia response. Cell. Signalling 24, $35-43$.

(35) Højfeldt, J. W., Agger, K., and Helin, K. (2013) Histone lysine demethylases as targets for anticancer therapy. Nat. Rev. Drug Discovery $12,917-30$.

(36) Zhang, Q. J., Chen, H. Z., Wang, L., Liu, D. P., Hill, J. A., and Liu, Z. P. (2011) The histone trimethyllysine demethylase JMJD2A promotes cardiac hypertrophy in response to hypertrophic stimuli in mice. J. Clin. Invest. 121, 2447-2456.

(37) Ng, S. S., Kavanagh, K. L., McDonough, M. A., Butler, D., Pilka, E. S., Lienard, B. M., Bray, J. E., Savitsky, P., Gileadi, O., von Delft, F., Rose, N. R., Offer, J., Scheinost, J. C., Borowski, T., Sundstrom, M., Schofield, C. J., and Oppermann, U. (2007) Crystal structures of histone demethylase JMJD2A reveal basis for substrate specificity. Nature 448, 87-91.

(38) Hillringhaus, L., Yue, W. W., Rose, N. R., Ng, S. S., Gileadi, C., Loenarz, C., Bello, S. H., Bray, J. E., Schofield, C. J., and Oppermann, U. (2011) Structural and evolutionary basis for the dual substrate selectivity of human KDM4 histone demethylase family. J. Biol. Chem. 286, 41616-41625.

(39) Chowdhury, R., Yeoh, K. K., Tian, Y.-M., Hillringhaus, L., Bagg, E. A., Rose, N. R., Leung, I. K. H., Li, X. S., Woon, E. C. Y., Yang, M., McDonough, M. A., King, O. N., Clifton, I. J., Klose, R. J., Claridge, T. D. W., Ratcliffe, P. J., Schofield, C. J., and Kawamura, A. (2011) The oncometabolite 2-hydroxyglutarate inhibits histone lysine demethylases. EMBO Rep. 12, 463-469.

(40) Black, J. C., Atabakhsh, E., Kim, J., Biette, K. M., Van Rechem, C., Ladd, B., Burrowes, P. D., Donado, C., Mattoo, H., Kleinstiver, B. P., Song, B., Andriani, G., Joung, J. K., Iliopoulos, O., Montagna, C., Pillai, S., Getz, G., and Whetstine, J. R. (2015) Hypoxia drives transient site-specific copy gain and drug-resistant gene expression. Genes Dev. 29, 1018-1031.

(41) Van Rechem, C., Black, J. C., Abbas, T., Allen, A., Rinehart, C. A., Yuan, G.-C., Dutta, A., and Whetstine, J. R. (2011) The SKP1Cul1-F-box and leucine-rich repeat protein 4 (SCF-FbxL4) ubiquitin ligase regulates lysine demethylase 4A (KDM4A)/Jumonji domaincontaining 2A (JMJD2A) protein. J. Biol. Chem. 286, 30462-30470.

(42) Williams, S. T., Walport, L. J., Hopkinson, R. J., Madden, S. K., Chowdhury, R., Schofield, C. J., and Kawamura, A. (2014) Studies on the catalytic domains of multiple JmjC oxygenases using peptide substrates. Epigenetics 9, 1596-1603.

(43) Lohse, B., Helgstrand, C., Kristensen, J. B. L., Leurs, U., Cloos, P. A. C., Kristensen, J. L., and Clausen, R. P. (2013) Posttranslational modifications of the histone 3 tail and their impact on the activity of histone lysine demethylases in vitro. PLoS One 8, e67653.

(44) Pack, L. R., Yamamoto, K. R., and Fujimori, D. G. (2016) Opposing Chromatin Signals Direct and Regulate the Activity of Lysine Demethylase 4C (KDM4C). J. Biol. Chem. 291, 6060-6070.

(45) Hohl, M., Wagner, M., Reil, J.-C., Müller, S.-A., Tauchnitz, M., Zimmer, A. M., Lehmann, L. H., Thiel, G., Böhm, M., Backs, J., and Maack, C. (2013) HDAC4 controls histone methylation in response to elevated cardiac load. J. Clin. Invest. 123, 1359-1370.

(46) Lee, H. Y., Yang, E. G., and Park, H. (2013) Hypoxia enhances the expression of prostate-specific antigen by modifying the quantity and catalytic activity of Jumonji C domain-containing histone demethylases. Carcinogenesis 34, 2706-2715.
(47) Gossen, M., Freundlieb, S., Bender, G., Müller, G., Hillen, W., and Bujard, H. (1995) Transcriptional activation by tetracyclines in mammalian cells. Science 268, 1766-1769.

(48) Deuschle, U., Meyer, W. K., and Thiesen, H. J. (1995) Tetracycline-reversible silencing of eukaryotic promoters. Mol. Cell. Biol. 15, 1907-1914.

(49) King, O. N. F., Li, X. S., Sakurai, M., Kawamura, A., Rose, N. R., Ng, S. S., Quinn, A. M., Rai, G., Mott, B. T., Beswick, P., Klose, R. J., Oppermann, U., Jadhav, A., Heightman, T. D., Maloney, D. J., Schofield, C. J., and Simeonov, A. (2010) Quantitative highthroughput screening identifies 8-hydroxyquinolines as cell-active histone demethylase inhibitors. PLoS One 5, e15535. 